\title{
HAYKA 21.0
}

\section{ИЛЛОКУТИВНАЯ НАПРАВЛЕННОСТЬ И РЕФЕРЕНЦИАЛЬНАЯ СПЕЦИФИКА ЯЗЫКОВОЙ ИГРЫ}

\author{
Н.Ю. Тимофеева \\ Крымский федеральный университет имени В.И. Вернадского \\ проспект Академика Вернадского, 4, г. Симферополь, Россия, 295007
}

Вопрос о сущности феномена языковой игры остается актуальным с момента введения термина в научный оборот в работах Е.А. Земской, трактующей языковую игру как актуализацию эстетической стороны языковой деятельности. Современный подход к проблематике языковой игры, как правило, осуществляется с опорой на комическую природу явления. При этом наблюдается доминирование текстового материала в исследованиях этого феномена, хотя речевой вариант явления также требует проработки. В статье предлагается применение прагматических параметров к материалу живой спонтанной речи с целью разграничения собственно игровых единиц и креативных номинаций. Материалом выступают записи живой устной речи крымских жителей из картотеки кафедры русского, славянского и общего языкознания Таврической Академии Крымского федерального университета. Материал подвергается дискурсивному, словообразовательному и семантическому анализу. Исходным положением исследования выступает противопоставление фатической и референтивной (когнитивной) функций языка. Иллокутивная направленность высказывания в речевом потоке обусловливается конситуацией и отношениями между коммуникантами. При этом наблюдается неравномерное распределение иллокутивной нагрузки на каждый из компонентов речевого акта. Игровой характер некоторых речевых единиц снижает информативность высказывания, конфигурируя дискурс вокруг контакта, а не сообщения, как то подразумевает эстетический критерий в определении языковой игры. В ходе речевого взаимодействия фатического типа его участники вербальными средствами реализуют невербальные цели: эмпатически разделить состояние оппонента, подчеркнуть близость отношений, установить контакт с незнакомым человеком, расположить его к коммуникации. Этот тип организации дискурса свидетельствует об особой специфике референциальной составляющей высказываний, содержащих нестандартные речевые единицы. Соотнесение этих единиц с действительностью не сводится к прямой референциальной сумме отдельных знаков, а устанавливается опосредованно - через дискурсивные дескрипторы, указывающие на цель речевого действия и способы его осуществления. Анализ референциальной специфики речевых единиц игрового характера продемонстрировал различную степень соотношения интра- и экстралингвистических факторов организации дискурса, что позволило сделать вывод об ограниченности сферы применения термина «языковая игра» фактами фатической направленности.

Ключевые слова: речевой акт, языковая игра, фатическая и метаязыковая функции, иллокуция, референт, номинация 


\section{ВВЕДЕНИЕ}

Проблемы объема термина «языковая игра» возникают вместе с его появлением в отечественной лингвистике в работах Е.А. Земской [1. С. 175]. Автор трактует содержание термина как намеренные отклонения от языковых норм, «которые имеют место, когда говорящий „играет“ с формой речи, когда свободное отношение к форме речи получает эстетическое задание, пусть даже самое скромное. Это может быть и незатейливая шутка, и более или менее удачная острота, и каламбур, и разные виды тропов (сравнения, метафоры, перифразы и т.д.)» [1. Там же]. Дальнейшая практика применения термина в научной литературе уточняет его содержание как разновидность комического [2; 3]. Следующий этап изучения феномена связан с обращением внимания на его воздейственную силу [4], особенно в сфере СМИ [5]. Интенсивность использования термина, однако, не повлияла на проработку его объема. В последних исследованиях, посвященных явлениям языковой игры, отмечается «размытость» понятия [6. С. 51; 7. С. 45]. При этом невозможно игнорировать тот факт, что материалом изучения ЯИ в большинстве работ выступают тексты художественного и публицистического стилей $[4 ; 5 ; 8]$ в то время как речевая сторона ЯИ нуждается в равноценном изучении. Определенная систематизация речевого материала проведена в монографии О.Ю. Коноваловой «Языковая игра в разговорной русской речи», автор которой впервые рассматривает ЯИ с позиций прагмалингвистики, учитывая параметры говорящих и ситуативного контекста [9]. Однако само понятие ЯИ при этом остается непроясненным, поскольку в работе ставятся иные методологические задачи. Такое положение определяет актуальность рассмотрения ЯИ в аспекте его сущностного содержания с привлечением новых данных наблюдений устной речи. Предпринятое нами исследование, являясь логическим продолжением прагмалингвистического подхода к изучению ЯИ, имеет своей целью уточнение объема содержания понятия ЯИ путем сопоставления функций нестандартных языковых единиц в речевых актах.

\section{МАТЕРИАЛЫ И МЕТОДЫ}

Материалом исследования послужили записи фактов креативного характера из картотеки живой звучащей речи, создаваемой на кафедре русского, славянского и общего языкознания Таврической Академии Крымского федерального университета.

Материал подвергается дискурсивному, словообразовательному и семантическому анализу.

\section{РЕЗУЛЬТАТЫ}

Современная практика употребления термина ЯИ базируется на его дифференцирующих характеристиках, приводимых в определении Е.А. Земской: «свободное» отношение к форме языковой единицы и наличие эстетического задания. При этом в дефиниции Е.А. Земской фиксируется открытость видового ряда ЯИ: «...метафоры, перифразы и т.д.)» [1. С. 175]. Таким образом, понятие ЯИ на сегодняшний день объединяет под собой любые формы нестандартного употребления 
языка на разных его уровнях. Наличие эстетического задания соотносит высказывания, содержащие единицы ЯИ, с поэтической функцией языка [10. С. 47] и обусловливает возникновение данных форм в речевых актах с преобладанием такого структурного компонента речевого акта как сообщение [11. С. 202]. Эта соотносительность ЯИ с самим сообщением предполагает ее функциональную ограниченность, что противоречит фактам, изложенным в упомянутых выше работах Т.А. Гридиной, С.В. Ильясовой и О.Ю. Коноваловой.

Обобщая приведенные в этих работах данные, следует признать, что индивидуализированные, окказиональные единицы речи обладают различной интенциональной направленностью, или, в терминологии Дж. Сёрля, различной иллокуцией [12. С. 62] и используются для реализации, по меньшей мере, трех функций языка - эстетической, апеллятивной и фатической. Кроме этого, факты нестандартного употребления языка используются как средство «деавтоматизации» [13. С. 76] общения с нарушением традиционной логики соотношения означаемого и означающего или сдвигом референции [14. С. 234], когда в процессе реализации иллокутивного намерения высказывания ослабевает референциальная однозначность отдельно взятой единицы [14. С. 231]. Иными словами, нестандартные единицы отличаются от стандартных в референциальном аспекте. Если согласиться с соображением, высказанным Т.Г. Винокур, о противопоставлении информационной и фатической функции языка [15] и присутствии в любом акте речи воздейственной функции [16], то его закономерным следствием становится разграничение нестандартных речевых единиц по конкретности их денотата и/или референта [17. С. 13-14]. Таким образом, при наблюдении живого процесса общения можно выявить случаи разной функциональной направленности высказываний, содержащих окказиональные формы, которые используются для усиления вербального воздействия при установлении или поддержании контакта или для особого оформления высказывания. Номинативная функция слова или выражения во всех случаях оказывается второстепенна или вообще игнорируется [18. С. 109].

Таким образом, собственно прагматическая, коммуникационная ценность нестандартных единиц речи оказывается различной, как и степень включения «игрового режима» в конкретном речевом акте. Отсутствие «у игр... правил пропозиционального содержания» [12. С. 74] в силу их «конститутивной» природы [Там же. С. 59] подчеркивает иллокутивное различие речевых актов («общение сообщение» [18. С. 136]) и становится основанием для выделения из массы окказионализмов собственно игровых форм.

По своему происхождению все инновации, образованные в потоке речи, однородны: они представляют собой результат нарушения словообразовательной или сочетаемостной модели, деструкцию соотношения означаемое - означающее [19. С. 75] или аномальную вербализацию плана содержания [20. С. 26]. Как правило, «сырьем» для подобных инноваций становятся нейтральные сочетания прилагательного и существительного, лексем одной лексико-тематической группы или одного лексико-семантического поля (метонимический тип ЯИ), члены одного 
синонимического ряда или таксоны одной гипонимической горизонтали, омонимы и антонимы, в том числе и омонимичные и антонимичные морфемы, а также паронимические ассоциаты, в том числе и иноязычные. То есть стимулом образования новой формы выступает актуализированная в момент высказывания языковая парадигматика разных уровней. Но при внешней структурной однородности (аномальности структуры) факты нестандартного осмысления парадигматики имеют функциональные отличия, обусловленные прагматикой ситуации. В этой связи совершенно закономерными представляются исследования, соотносящие изучение грамматики с социальными фактами, например, в рамках теории лингвистической вариативности [21].

Особую группу индивидуальных инноваций в нашем материале представляют контаминированные русско-крымскотатарские формы речевого этикета: алейкумпривет, селямствуйте, саламирую ('здравствуйте') и тематически примыкающие к ним обращения в кругу семьи: анашка (ана - кр.татарск. 'мама'), бабашка (баба - кр.татарск. 'папа'), баларики, баласенок (балалар - кр.татарск. 'дети'), а также подобные им контаминации онимов: Колотун-баба - 'Дед Мороз'. Явления этого ряда, на наш взгляд, возникают на основе межкультурной интерференции и как продукт полилингвальной [22. С. 24, 26-27] реальности многонационального Крыма. Функциональная специфика таких этикетных и реноминативных контаминантов, возникающих вне взаимной звуковой или структурной аттракции, заключается в обозначении национального добрососедства, манифестации межкультурного взаимодействия. Эти единицы исключительно фатической направленности дополняются разнообразными формами ЯИ в кругу близких. Такого рода высказывания как удивленно-восторженное Ого, как ты побородел! или сокрушенное Bom, бедасечка! или трансформированное имя собственное Маринадик (от Марина) не имеют никакого иного иллокутивного содержания как выражение добрых, приятельских отношений и выступают психологическими скрепами коммуникации.

Второй пример Bom, бедасечка! демонстрирует, что психологическое содержание некоторых речевых актов конкретизируется выражением эмпатии говорящего к респонденту: форма бедасечка реферирует не столько к нюансам самой ситуации, сколько к состоянию говорящих. Эмпатия в этом случае проявлена соотносительностью окказиональной и нормативной форм бедасечка и бедняжечка, значения которых имеют общий апперцепционный фон [23] как на уровне фреймовой схемы (nonacmь в беду - бедняжка), так и в системе лексико-семантического поля 'неприятность'. Аналогичный эмпатический заряд заложен в единице будняжка, возникающей в речи сокурсниц, одна из которых жалуется на усталость от будничной рутины. Смысловое ударение смещается на ласкательность аффикса, который, выступая показателем иллокуции [12. С. 62], обеспечивает большую контактность участников. Оба окказионализма бедасечка и будняжка по своей референтной диффузности близки к этикетным оборотам.

Несколько иначе фатическая функция реализуется в примерах Что ты так переживаешь, моя ойойойка? и в ласкательном обращении вампиреньш. Здесь 
эмпатическая иллокуция высказывания совмещена с намерением подчеркнуть особую интимность межгендерного общения, отсутствие дистанции между участниками, так как в обоих примерах инновации использованы в речи двадцатилетних молодых людей по отношению к их возлюбленным. Кроме обозначения иллокуции, и ойойойка, и вампиреныш содержат определенную характеристику адресата. Однако конкретность референции этих форм ослаблена [17. С. 81-82] их подчеркнутой эмотивностью: интенция говорящего, как и в примерах выше, актуализируется грамматически — категорией притяжательности местоимения в первом случае и уменьшительным аффиксом, апеллирующим к лексеме мальим, - во втором. Местоимение моя выполняет роль дискурсивного дескриптора, предопределяющего возникновение нестандартной единицы ойойойка как средства интимизации общения. Сочетание местоимения и нестандартного существительного позволяет лишний раз продемонстрировать и так понятное, открытое для реципиента состояния: 'я с тобой', 'мы вместе'. Аналогичным образом форма вампиреныш в контексте речевой ситуации реализует семантику словосочетания вредный мальим, которое имплицитно соотносимо с тем же притяжательным местоимением моя (ср.: вампиреныли - 'мой вредный малыш'). Функциональной доминантой данных речевых актов выступает контакт, а не номинация или сообщение. Следовательно, здесь мы имеет дело с фатической коммуникацией, в рамках которой возникают игровые единицы.

Подобный тип речевого взаимодействия представлен и во фразе молодой девушки У меня по отношению к нему нет самолюбия, есть только еголюбие, в которой направленность высказывания в целом и завершающий его окказионализм подчеркивают особый род контакта с не участвующем в диалоге, но иллокутивно доминирующем в нем третьим лицом. Неслучайно семантика окказионализма избыточна: предикативный вариант фразы У меня по отношению к нему нет самолюбия - я люблю его не снижает информативности описания отношений, однако говорящий избирает параллелизм форм само- его- любие, отказываясь от глагольной структуры в пользу дескрипции местоимения. Таким образом, иллокуция высказывания сводится к подчеркиванию особой фатики между говорящим и третьим лицом - объектом речи. В отличие от предыдущих примеров контакт как цель речевого акта здесь представлен опосредованно.

Нестандартные формы речевых действий оказываются более чем уместны при романтических отношениях, ибо флирт и ухаживания - это ситуация игры, эксперимента и экспромта. Игровая динамика этого типа коммуникации зафиксирована в пассаже Для влюбленных по вечерам катамараны превращаются в катароманы, после которых у этих молодых людей рождаются катаРоманчики. В этом примере дискурс организуется шагами словобразования: катаМаРан - катаР[a]Ман - катаРоман ЧИКи, причем в последнем отрезке происходит не только аффиксальное приращение значения, но и обыгрывание омонимии уменьшительной формы нарицательного существительного и имени собственного (романчик - Романчик). Весь фон апперцепции составляет воображаемое путешествие на катамаране - необычная отправная точка для любовного романа, а динамика ситуации обеспечивается структурной соотносительностью лексем. 
Если исходное слово - катамаран - неразложимое целое, то первое его производное - катароман - представляет собой окказиональный контаминант с нулевым (с точки зрения языковой системы) денотатом левой части. Нестандартность данной номинации предваряется глаголом превращаются, сигнализирующим о несоотносимости всего высказывания с внеязыковой действительностью. Второе производное - катаРоманчики - еще активнее сдвигает высказывание в зону доминирования такого компонента речевого акта, как сообщение. Если для первого производного допустимо толкование 'романы на катамаранах', то для второго подобная попытка - 'мальчики Романчики, рожденные на катамаранах’ - оказывается логическим и прагматическим нонсенсом. Таким образом, данное выражение реализует поэтическую функцию речи, отвлекаясь от диалоговой динамики в вербальное моделирование, по своему характеру родственное художественному творчеству. Безусловно, такими формами речевых действий не решаются задачи коммуникации, даже фатической направленности. Сообщение в роли доминанты речевого акта «оттесняет» говорящего и слушающего на позиции наблюдателей за возможностями речевой комбинаторики, которая в данном случае является и самой иллокуцией, и средством ее реализации.

В приведенных примерах очевидна иллокутивная разнонаправленность речевых актов: одни единицы речи используются как контактоустанавливающие [24. С. 318], другие - как средства интимизации общения, сокращения дистанции между собеседниками, третьи - как орудие вторичного моделирования, создания художественной реальности. Все эти виды иллокуции в речевой практике чаще комбинируются, чем дифференцируются. Однако так или иначе доминирует только один. На наш взгляд, при квалификации окказионального явления как единицы ЯИ следует опираться на противопоставление номинативного (когнитивного) и фатического вектора дискурса, дополняя эту процедуру анализом референциальной «наполненности» возникающих нестандартных единиц. Если обозначить условным центром коммуникации сообщение как внутренний «продукт» речевого взаимодействия, то действие иллокутивной силы окажется центробежным - направленным на участников и внеязыковую действительность или центростремительным - направленным на код, контакт или само сообщение. Чем дальше интенция речи от личности говорящих и параметров конситуации, тем больше в такой речи игрового «простора».

ЯИ подчас возникает как средство установления контакта в речи незнакомых друг другу людей. Так, окказионализм замечтательно, возникающий в спонтанном диалоге попутчиков в общественном транспорте, возбуждает заинтересованность слушающего, обеспечивая реализацию конативной функции языка [11. С. 200], а именно - вовлечение попутчика в общение. Bbl знаете, что иногда замечательно, может оказаться замечтательно?! Вы знаете такое слово, да? А знаете ли Вы, что сам Владимир Даль - мой родственник. Мой отец тоже Владимир Иванович, и тоже из Дании. Потомок Даля - представляете?! Существенно, что в процессе речи значение окказионализма, возникающего на основе паронимической аттракции (замечательно - замечТательно, как и в паре катамарань катароманы), остается непроявленным. Вместо обозначения гипотетического 
референта говорящий стремительно наращивает иллокутивную силу вовлечения реципиента в круг своих интересов метаязыкового характера. Дескриптором приведенного пассажа оказывается лексема слово, которое ассоциативно актуализировано в имени собственном В.И. Даля как важнейшая сфера его жизнедеятельности. Первоначальная иллокуция установления контакта и метакодовой проверки (что значит слово) сменяется референтивной, когнитивной иллокуцией при введении прецедентного имени, референт которого однозначен и «мысленное досье» [25. С. 46] которого активизируется говорящим в сознании реципиента. В следующей части высказывания направление иллокуции корректируется в сторону личности самого говорящего: сведения о его происхождении позитивно воспринимаются заинтригованным сознанием слушающего. ЯИ в этом случае одновременно выполняет фатическую задачу вступления в контакт и участвует в конфигурировании дискурса.

Под воздействием закона языковой экономии [26. С. 126] окказиональные единицы используются и в целях номинации. Прагматика таких ситуаций более определенна, иллокуция направлена на осуществление коммуникации в ее первоначальной, когнитивно-номинативной функции. Сравним ранее приведенные примеры с окказиональными формами духовейчик, крясавчик, таксист, журфакер. В первом случае речь идет о вентиляторном обогревателе, имеющим номенклатурное наименование термовентилятор, которое, тем не менее, может оставаться неизвестным автору окказионализма - женщине восьмидесяти лет.

Фраза, в структуре которой возникает окказиональный синоним, представляет собой комментарий физических действий: Сейчас включим духовейчик душок сразу пойдет. В структуре высказывания окказионализм имеет определенный референт - вид бытового прибора, на который направлена деятельность говорящего, что отличает это средство интимизации общения от предыдущих. Определенность референции характерна и для лексемы крясавчик - эквиваленту словосочетания красивый селезень, в котором второй компонент замещен смежным звукоподражанием кря и вложен в семантику первого. Такая структурная «упаковка» [27. С. 21; 28. С. 272] смыслов позволяет экономить речевые усилия и при этом способствует реализации дополнительных задач говорящего. Обращенная от лица девушки к подруге фраза Посмотри, какой крясавчик! попутно обращает внимание на самого говорящего, его стиль выражения мысли.

Референтивная функция характерна и для выражений с окказионализмами таксист — 'кобель породы такса' и журфакер — 'студент факультета журналистики’. Однако условия их функционирования имеют отличия, связанные с приемами образования этих форм. Речевая единица таксист при описании собаки в общении подруг возникает как омоним существующего названия лица по роду занятий: У твоей сестры такой мильий рыжсий таксист. Игровой момент здесь обусловлен, с одной стороны, поддержанием дружеского контакта, стремлением пошутить, а с другой — лексема заполняет лакуну номинации, поскольку в языке нет словоформы мужского рода для существительного такса. Речевая единица журфакер образована как результат стяжения трехчленного словосочетания студент факультета журналистики по иноязычной модели с форман- 
том -ер- от сокращения журфак - факультет журналистики. Кроме номинативного аспекта в окказионализме актуализирован иронично-обсценный дискурс, поскольку наблюдается структурное пересечение с англоязычным ругательством fuck-er, что ограничивает использование русского окказионализма определенной возрастной группой.

Подобные факты нестандартной номинации в силу их референциальной определенности, на наш взгляд, отличаются от фактов контактоустанавливающего характера большей прагматической обусловленностью и иной структурообразующей доминантой - контекстом внеязыковой действительности («положением дел», по Дж. Сёрлю [12. С. 74]), а не самим сообщением. В живой речи действие закона коммуникативной кооперации [29. С. 122] предопределяет ведущее положение контакта в иерархии компонентов речевого акта и ограничивает функциональный диапазон ЯИ фатической иллокуцией.

\section{ВывОды}

Рассмотренные примеры нестандартного использования языка в спонтанном общении могут быть объединены в две группы по характеру референтов и в три по своей иллокутивной направленности: единицы диффузной референции и единицы конкретной референции - с одной стороны, и контактоустанавливающие единицы, единицы, моделирующие художественную реальность, и нестандартные единицы однословной номинации - с другой стороны. При этом факты поэтического моделирования в спонтанной речи должны быть рассмотрены отдельно, как отвечающие параметрам эстетического обращения с языком или, словами А.Р. Будагова - «воздействия на язык» [30. С. 56]. Феномен ЯИ в свете изложенных результатов анализа речевых актов спонтанной коммуникации проявляет функциональную ограниченность, которая проявляется по мере усиления номинативного аспекта речи. Применение иллокутивного параметра может послужить основой для идентификации единиц ЯИ в массе окказионализмов и уточнения содержания термина.

\section{(C) Тимофеева Н.Ю.}

Дата поступления: 14.10.2017

Дата приема в печать: 10.03.2018

\section{БИБЛИОГРАФИЧЕСКИЙ СПИСОК}

1. Земская Е.А., Китайгородская М.В., Розанова Н.Н. Языковая игра // Русская разговорная речь. М., 1983. С. $172-214$.

2. Нухов С.Ж. Языковая игра в словообразовании. На материале лексики английского языка: дис. ... докт. филол. наук. М., 1997.

3. Санников В.3. Русский язык в зеркале языковой игры. М.: Школа «Языки русской культуры», 1999.

4. Гридина Т.А. Языковая игра: стереотип и творчество. Екатеринбург: Наука, 1996.

5. Ильясова С.В., Амири Л.П. Языковая игра в коммуникативном пространстве СМИ. М.: Наука, Флинта, 2015.

6. Лебедева Е.Б. Уточнение понятия «языковая игра» в лингвистике // Язык и культура. 2014. № 4. C. 48 - 63 . 
7. Каргаполова И.А. «Языковая игра» в лексикографическом и научном освещении: концептуально-методологический анализ // Известия Российского государственного педагогического университета им. А.И. Герцена. Серия филологические и исторические науки, культурология. 2007. № 9 (47). С. 44-53.

9. Лингвистика креатива-2. Екатеринбург: ФГБОУ ВПО «Урал. гос. пед. ун-т», 2012.

9. Коновалова Ю.О. Языковая игра в современной русской разговорной речи. Владивосток: Изд-во ВГУЭС, 2008.

10. Петров A.B. Реализация творческого потенциала в речи крымчан // Современная картина мира: крымский контекст. Симферополь, 2017. С. 45-68.

11. Якобсон Р.О. Лингвистика и поэтика // Структурализм: за и против. М.: Прогресс, 1975. C. $193-231$.

12. Сёрл Дж. Что такое речевой акт? // Философия языка. М.: Едиториал УРСС, 2010. C. $56-75$.

13. Норман Б. Ю. Грамматика говорящего: от замысла к высказыванию. М.: Книжный дом «ЛИБРОКОМ», 2011.

14. Клюев Е. В. Речевая коммуникация. М.: РИПОЛ КЛАССИК, 2002.

15. Винокур Т.Г. Информативная и фатическая речь как выражение разных коммуникативных намерений говорящего и слушающего // Русский язык в его функционировании. Коммуникативно-прагматический аспект. М.: Наука, 1993. С. 5-29.

16. Аллен Дж., Перро Р. Выявление коммуникативного намерения, содержащегося в высказывании // Новое в зарубежной лингвистике. М.: Прогресс, 1986. Вып. 17. Теория речевых актов. С. $322-362$.

17. Падучева Е.В. Высказывание и его соотнесенность с действительностью. М.: Наука, 1985.

18. Винокур Т.Г. Говорящий и слушающий. Варианты речевого поведения. М.: Наука, 1993.

19. Винокур Т.Г. Закономерности стилистического использования языковых единиц. М.: Книжный дом «ЛИБРОКОМ», 2009.

20. Радбиль Т.Б. Языковые аномалии в художественном тексте: Андрей Платонов и другие. М.: Флинта, 2012.

21. Fassold Ralf W. \& Preston.Dennis R. The Psychological Unity of Inherent Variability: Old Occam Whips out His Rasor. Sociolinguistic variation: Theories, Methods and Appications. New York: Cambridge University Press. 2007, 45-69.

22. Богданович Г.Ю. Еще раз о тексте, дискурсе, языковой картине мира в полилингвокультурной ситуации // Современная картина мира: крымский контекст. Симферополь, 2017. C. $12-31$.

23. Якубинский Л.П. О диалогической речи // Якубинский Л.П. Избранные работы: Язык и его функционирование. М., 1986. С. 17-58.

24. Бенвенист Э. Формальный аппарат высказывания // Э. Бенвенист. Общая лингвистика / под ред. Ю. С. Степанова. М.: Прогресс, 1974. С. 311-319.

25. Шмелев А.Д. Русский язык и внеязыковая действительность. М.: Языки славянской культуры, 2002.

26. Мартине A. Механизмы фонетических изменений: Проблемы диахронической фонологии. M.: URSS, 2006.

27. Johnson M. The Body in the Mind: The Bodily Basis of Meaning, Imagination, and Reason. Chicago: Chicago University Press, 1987.

28. Lakoff G. Women, Fire and Dangerous Things: What Categories Reveal about the Mind. Chicago - London: University of Chicago Press, 1987.

29. Грайс Г.П. Логика и речевое общение // Новое в зарубежной лингвистике. Вып. 16. Лингвистическая прагматика. М.: Прогресс, 1985. С. 217-237.

30. Будагов А.Р. Человек и его язык. М.: МГУ, 1976. 


\title{
ILLOCUTIONARY DIRECTION AND REFERENTIAL SPECIFICS OF LANGUAGE GAME
}

\author{
Natalia Y. Timofeeva \\ V.I. Vernadsky Crimean Federal University \\ pr. Vernadskogo 4, Simferopol, Republic of Crimea, Russia, 295007
}

\begin{abstract}
The definition of the term "language game" stays an actual problem of linguistics, as the term essence was not clearly revealed under the first usage at E.A. Zemskaya's researches, where the phenomenon had got an aesthetic interpretation appealed to the poetic function of language. Contemporary science treat facts of language game as comic ones. Simultaneously language game researches are based on texts material, whereas speech aspect need a careful examining. In this case, there is a dining material texts in the study of this phenomenon, although the roar of the variant of the phenomenon also requires study. The article proposes the use of pragmatic options for a living material spontaneous speech with the aim of delineating the actual game pieces and the creative category. Records of a live speech of inhabitants of St. crimes from cards of chair of the Russian, Slavic and General linguistics Trick of Academy of the Crimean Federal University act as a material. The material is subjected to discourse, word-formation and semantic analysis. Shot polonium research opposes the fate and referent (cognitive) functions of the language. Highlight the statements about the provence in the flow is subject to consultation and actions between messages. At the same time, there is a nerve distribution of the load distribution on each of the components of the act. The playful nature of some of the units reduces informative statements, customize discuss around the contact rather than the message, as that implies a static criterion in determining the language game. During interaction about the type of the participants orally by means of neural realist objectives: empathy is to share state of the opponent, to emphasize the closeness of the relationship, to establish contact with a stranger, to make him communication. This type of organization discuss attests to the special specificity of the preferential component statements containing the standard receive units. Calms these units with a daily does not sort to the direct preferential individual character sum, but is set indirectly - through discourse descriptors indicating the purpose of the action and the ways of its implementation. Analysis of preferential specific rev units grow character to demonstrate a relic of the degree of correlation of intra-factors discuss organization extras and that allowed to draw a conclusion about the Orient of the scope of the terminal "language game" facts fate of Provence.
\end{abstract}

Key words: speech act, language game, the phatic and the metalingual functions, illocution, referent, nomination

\section{REFERENCES}

1. Zemskaya, E.A., Kitaigorodskaya, M.V., Rozanova, N.N. (1983). Language game. In Russian Colloquial Speech. Moscow, 172-214. (In Russ.).

2. Nuhov, S.Zh. (1997). Language game in derivation: jn the base of English language [dissertation]. Moscow. (In Russ.).

3. Sannikov, V.Z. (1999). Russian in the mirror of languge game. Moscow: Shkola "Yazyki russkoj kul'tury" publ. (In Russ.).

4. Gridina, T.A. (1996). Language game: stereotype and creation. Ekaterinburg: Nauka publ. (In Russ.).

5. Il'yasova, S.V., Amiri, L.P. (2015). Language game in communicative area of mass-media. M.: Nauka, Flinta. publ. (In Russ.). 
6. Lebedeva, E.B. (2014). Clarification to the term "language game" in linguistics. Yazyk i Kul'tura, 4, 48-63. (In Russ.).

7. Kargapolova, I.A. (2007). "Language game" in lexicographic and scientific aspects: conceptualmethodological analysis. IZVESTIA: Herzen University Journal of Humanities and Sciences, 9 (47), 44-53. (In Russ.).

8. Linguistics of creation-2. (2012). Ekaterinburg: Ural State Pedogogical Institute Publ. (In Russ.).

9. Konovalova, Yu. O. (2008). Language game in modern Russian colloquial speech. Vladivostok: VGUES publ. (In Russ.).

10. Petrov, A.V. (2017). Realization of Creative Potential in Colloquial Speech of Creamian inhabitants. In Modern World-View: Vol. 1. Simferopol', 45-68. (In Russ.).

11. Yakobson, R.O. (1975). Linguistics and Poetics. In Strukturalizm: pro and contra. Moscow: Progress publ., 193-231. (In Russ.).

12. Searle, J.R. (2010). What is a Speech Act? In The Philosophy of Language: edited by J.R. Searle. Moscow: Editorial URSS publ., 56-75. (In Russ.).

13. Norman, B.Yu. (2011). Speaker's grammatics: from idea to utterance. Moscow: "LIBROKOM" publ. (In Russ.).

14. Klujev, E.V. (2002). Speech Communication. Moscow: RIPOL CLASSIC publ. (In Russ.).

15. Vinokur, T.G (1993). Information and fatic speech as the expression of communicative intentions of speaker. In Russian Language in its Function: Communicative-Pragmatic Aspect. Moscow: Nauka publ., 5-29. (In Russ.).

16. Allen, J.F. and Perrault C.R. (1986). Analyzing Intention in Utterances. In News of West Linguistics. Vol. 17. Teoriya Rechevykh Aktov. Moscow: Progress publ., 322-362. (In Russ.)

17. Paducheva, E.V. (1985). Utterance and its Reference. Moscow: Nauka publ. (In Russ.).

18. Vinokur, T.G. (1993). Speaker and Hearer: Variants of Speech Behavior. Moscow: Nauka publ. (In Russ.).

19. Vinokur, T.G. (2009). Regularities of Stylistic Usage of Language Units. Moscow: "LIBROKOM" publ. (In Russ.).

20. Radbil', T.B. Language anomaly in art text: Anrej Platonov and others. Moscow: Flinta publ. (In Russ.).

21. Fassold, Ralf W. \& Preston Dennis R. (2007). The Psychological Unity of Inherent Variability: Old Occam Whips out His Rasor. In Sociolinguistic variation: Theories, Methods and Appications. New York: Cambridge University Press., 45-69.

22. Bogdanovich, G.Yu. (2017). Once more about text, discourse and world-viewin polylingual situation. In Modern World-View: Vol. 1. Simferopol', 12-31. (In Russ.).

23. Jakubinskij, L.P. (1986). About dialogic speech. In: Selected Works. Language and its Function. Moscow, 17-58. (In Russ.).

24. Benveniste Emile. (1974). The Formal Apparatus of Enancuation. In: General Linguistics. Moscow: Progress publ. 311-319. (In Russ.).

25. Shmeljov, A.D. (2002). Russian Language and Extralinguistic Reality. Moscow: Jazyki Slavjanskoj Kul'tury publ. (In Russ.).

26. Martinet, A. (2006). Mechanism of Phonetic Changes: Problems of Diahronic Phonology. Moscow: URSS publ.

27. Johnson, M. (1987). The Body in the Mind: The Bodily Basis of Meaning, Imagination, and Reason. Chicago: Chicago University Press. publ.

28. Lakoff G. (1987). Women, Fire and Dangerous Things: What Categories Reveal about the Mind. Chicago-London: University of Chicago Press.

29. Grice, H. Paul (1985). Logic and Conversation. In News of West Linguistics.Vol. 17. Linguistic Pragmatics. Moscow: Progress publ., 217-237. (In Russ.).

30. Budagov, A.R. (1976). Men and his Language. Moscow: Moscow State University publ. 


\section{Для цитирования:}

Тимофеева Н.Ю. Иллокутивная направленность и референциальная специфика языковой игры // Вестник Российского университета дружбы народов. Серия: Теория языка. Семиотика. Семантика, 2018. Т. 9. № 2. С. 451—462. doi: 10.22363/2313-2299-2018-9-2-451-462.

\section{For citation:}

Timofeeva N.Y. (2018). Illocutionary direction and referential specifics of language game. RUDN Journal of Language Studies, Semiotics and Semantics, 9 (2), 451-462. doi: 10.22363/2313-22992018-9-2-451-462.

Natalia Y. Timofeeva, 2018. RUDN Journal of Language Studies, Semiotics and Semantics, 9 (2), 451-462. doi: 10.22363/2313-2299-2018-9-2-451-462.

\section{Сведения об авторе:}

Тимофеева Наталья Юрьевна, аспирант кафедры русского, славянского и общего языкознания Крымского федерального университета им. В.И. Вернадского; научные интересы: социолингвистика, речевая коммуникация, прагмалингвистика; e-mail: natashanorge@mail.ru

\section{Bio Note:}

Timofeeva Natalia Yurievna, post-graduated student of the Department of Russian, Slavic and General Linguistics at V.I. Vernadsky Crimean Federal University; scientific interests: sociolinguistics, speech communication, pragmalinguistics; e-mail: natashanorge@mail.ru 